\title{
The Mostafa Maged maneuver to prevent and control post-partum haemorrhage during normal vaginal delivery
}

\author{
Mostafa Maged Ali ${ }^{1 *}$, Laila Ezzat Abdelfattah ${ }^{2}$
}

\author{
${ }^{1}$ Department of Obstetrics and Gynecology, Ministry of Health, Fayoum, Egypt \\ ${ }^{2}$ Department of Obstetrics and Gynecology, Fayoum University Hospital, Fayoum, Egypt
}

Received: 01 February 2022

Accepted: 25 February 2022

\section{*Correspondence:}

Dr. Mostafa Maged Ali,

E-mail: supermostafa200@yahoo.com

Copyright: (C) the author(s), publisher and licensee Medip Academy. This is an open-access article distributed under the terms of the Creative Commons Attribution Non-Commercial License, which permits unrestricted non-commercial use, distribution, and reproduction in any medium, provided the original work is properly cited.

\begin{abstract}
Atonic post-partum haemorrhage ( $\mathrm{PPH})$ is one of the most challenging complications of normal delivery process. There are many maneuvers applied to the atonic uterus for controlling the blood loss and conserving the uterus from hysterectomy process. There are pharmacological and surgical methods to control the bleeding. In this study, we introduce the Mostafa Maged technique to prevent and control post-partum bleeding during vaginal delivery. It is so simple and not-costly method.
\end{abstract}

Keywords: Mostafa Maged technique, Postpartum bleeding, Normal delivery, Atony

\section{INTRODUCTION}

PPH is commonly defined as blood loss exceeding 1000 milliliters after vaginal birth or cesarean section. ${ }^{1} \mathrm{PPH}$ is often classified as primary/immediate/early (occurring within 24 hours of birth) or secondary/delayed/late (occurring from more than 24 hours post birth to up to 12 weeks postpartum).

Risk factors for PPH are_infection, overdistention, high parity, fibroids, fetal macrosomia, retained parts of placenta, coagulation abnormalities etc. ${ }^{2}$

Atony, which is the main point in our manuscript, may be related to overdistention of the uterus, infection, placental abnormalities, or bladder distention. ${ }^{3}$

The medications most commonly used in PPH management are uterotonic agents as oxytocin, methergin, mesotac and carbetocin. ${ }^{4}$

There are many other options surgically, rather than medications, used to control bleeding in catastrophic conditions as Bakri balloon, internal iliac artery ligation, hysterectomy which is preserved as last option. ${ }^{5}$

\section{CASE SERIES}

The research protocol was approved by the university and ethics committee before the study began. All human participants gave written informed consent before the study began.

They are ten young patients. They are all pregnant females (primigravida and multi-gravida). Their mean age is 29.7 years old; their mean gestational age is 37.3 weeks.

The Mostafa Maged maneuver has been applied to those all-female patients to prevent post-partum bleeding in normal delivery. The Mostafa Maged technique is applied by: (Description of the new Mostafa Maged technique): First, placing our right hand to the posterior fornix of vaginal canal trying to cuddle the lower part of uterus compressing the anterior and posterior walls of the uterus. Second, placing our left hand over the fundus of the uterus and the posterior wall of uterus from the abdominal part. 
Third, by our two hands, trying to grasp the whole uterus by our two hands abdominally and vaginally against the symphysis pubis as if the uterus is cuddling the symphysis pubis bone and, in this way, we try to get the anterior and posterior walls against each other and reducing the intracavitary space so we prevent the expansion of the uterus. As mentioned in the Figure 1, illustrates the Mostafa Maged technique.

As mentioned in Table 1, they are the data about patients included in this study.

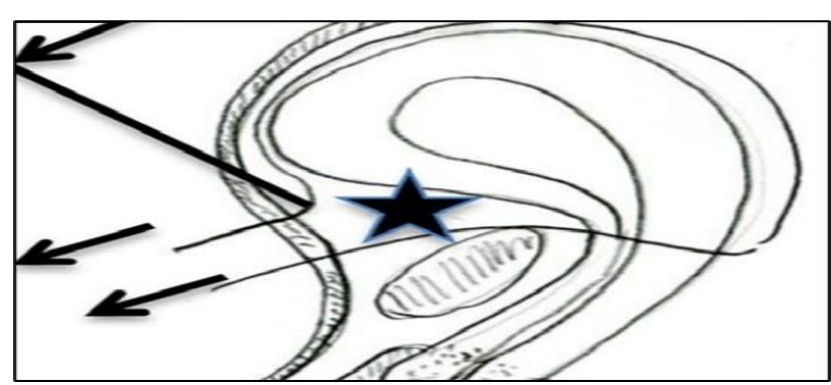

Figure 1: Grasping uterus against the symphysis pubis.

Table 1: Data of patients included in this study.

\begin{tabular}{|lllllllllll}
$\begin{array}{l}\text { Age } \\
\text { (years) }\end{array}$ & $\begin{array}{l}\text { Weight } \\
\text { (kg) }\end{array}$ & Height & $\begin{array}{l}\text { BMI } \\
\left(\mathbf{K g} / \mathbf{m}^{2}\right)\end{array}$ & $\begin{array}{l}\text { No. of } \\
\text { feti }\end{array}$ & $\begin{array}{l}\text { Pads } \\
\text { full of } \\
\text { blood }\end{array}$ & $\begin{array}{l}\text { Systolic } \\
\text { blood } \\
\text { pressure }\end{array}$ & $\begin{array}{l}\text { Diastolic } \\
\text { blood } \\
\text { pressure }\end{array}$ & $\begin{array}{l}\text { G. age } \\
\text { (weeks) }\end{array}$ & Parity & Episiotomy \\
\hline $\mathbf{2 5}$ & 80 & 1.65 & 29.3 & 2 & 2 & 110 & 70 & 32 & M & N \\
\hline $\mathbf{2 1}$ & 85 & 1.65 & 31.2 & 1 & 1 & 100 & 80 & 37 & PG & T \\
\hline $\mathbf{2 2}$ & 79 & 1.65 & 29 & 1 & 2 & 100 & 70 & 38 & PG & T \\
\hline $\mathbf{2 6}$ & 80 & 1.65 & 29.3 & 1 & 2 & 100 & 80 & 37 & M & N \\
\hline $\mathbf{2 5}$ & 78 & 1.65 & 28.6 & 1 & 2 & 90 & 60 & 40 & M & N \\
\hline $\mathbf{2 7}$ & 80 & 1.65 & 29.3 & 1 & 2 & 100 & 75 & 38 & M & N \\
\hline 37 & 80 & 1.65 & 29.3 & 1 & 3 & 110 & 80 & 37 & PG & T \\
\hline 38 & 80 & 1.65 & 29.3 & 1 & 2 & 115 & 70 & 38 & M & N \\
\hline 38 & 78 & 1.65 & 28.6 & 1 & 2 & 110 & 90 & 38 & M & N \\
\hline 38 & 80 & 1.65 & 29.3 & 1 & 2 & 120 & 80 & 38 & M & N \\
\hline
\end{tabular}

$\mathrm{N}$ : episiotomy not taken, M: Multipara, PG: Primigravida, T: Episiotomy taken.

\section{DISCUSSION}

Obstetric hemorrhage remains a major cause of maternal morbidity and mortality. The highest percentages of maternal deaths occur in the immediate postpartum period. Approximately $75 \%$ of PPHs are secondary to uterine atony. $^{6}$

Transfusion and anemia are sometimes used as markers for the amount of blood loss. The outcomes of intensive care unit (ICU) admission and extended hospitalization are used as indicators of maternal morbidity. Severe hemorrhage can lead to hysterectomy and death. ${ }^{7}$

Uterine atony is the primary direct cause of maternal morbidity globally. The active management of the third stage of labor with uterotonics reduces the risk of $\mathrm{PPH}{ }^{8}$

In this study, we introduce the Mostafa Maged technique to prevent and control post-partum bleeding during vaginal delivery in this paper we have introduced some cases which reveal the simplicity and effectiveness and possibility of applying this technique.

\section{CONCLUSION}

The Mostafa Maged maneuver is a simple technique used to prevent the post-partum haemorrhage in thin, not obese patient, this technique can be used in those who underwent the normal delivery as an alternative method to bimanual compression method. This maneuver needs more studies to evaluate its effectiveness in normal delivery.

Funding: No funding sources

Conflict of interest: None declared

Ethical approval: Not required

\section{REFERENCES}

1. John M. Eisenberg Center for Clinical Decisions and Communications Science. Management of Postpartum Hemorrhage: Current State of the Evidence. 2016.

2. Wormer KC, Jamil RT, Bryant SB. Acute Postpartum Hemorrhage. 2022.

3. Active management of the third stage of labour: prevention and treatment of postpartum hemorrhage: No. 235 October 2009 (Replaces No. 88, April 2000). Int J Gynaecol Obstet. 2010;108:258-67.

4. WHO Recommendations for the Prevention and Treatment of Postpartum Haemorrhage. 2012. Available at https://www.ncbi.nlm.nih.gov/books/ NBK535972. Accesses on 3 January 2022.

5. Abdul-Kadir R, McLintock C, Ducloy AS. Evaluation and management of postpartum hemorrhage: consensus from an international expert panel. Transfusion. 2014.

6. Anderson FWL. Maternal mortality: an enduring epidemic. Clin Obstetr Gynecol. 2009;52(2):214-23. 
7. Gizzo S, Saccardi C, Patrelli TS. Fertility rate and subsequent pregnancy outcomes after conservative surgical techniques in postpartum hemorrhage: 15 years of literature. Fertil Steril. 2013;99:2097-107.

8. Miller S, Lester F, Hensleigh P. Prevention and treatment of postpartum hemorrhage: new advances for low-resource settings. J Midwifery Women's Health. 2004;49(4):283-92.
Cite this article as: Ali MM, Abdelfattah LE. The Mostafa Maged maneuver to prevent and control post-partum haemorrhage during normal vaginal delivery. Int J Reprod Contracept Obstet Gynecol 2022;11:xxx-xx. 